\title{
Test of a Novel Streptococcus pneumoniae Serotype 6C Type Specific Polyclonal Antiserum (Factor Antiserum 6d) and Characterisation of Serotype 6C Isolates in Denmark
}

Lotte Lambertsen ${ }^{1 *}$, Mette B Kerrn²

\begin{abstract}
Background: In 2007, Park et al. identified a novel serotype among Streptococcus pneumoniae serogroup 6 which they named serotype 6C. The aim of this study was to evaluate with the Neufeld test a novel S. pneumoniae serotype 6C type specific polyclonal antiserum. In addition, serotype 6C isolates found in Denmark in 2007 and 2008 as well as eight old original serotype 6A isolates were characterised.

Methods: In this study, 181 clinical Streptococcus pneumoniae isolates from Denmark 2007 and 2008 were examined; 96 isolates had previously been typed as serotype 6A and 85 as serotype 6B. In addition, eight older isolates from 1952 to 1987, earlier serotyped as 6A, were examined. Serotype 6C isolates were identified by PCR and serotyping with the Neufeld test using the novel type specific polyclonal antiserum, factor antiserum $6 \mathrm{~d}$, in addition to factor antisera 6b, 6b* (absorbed free for cross-reactions to serotype 6C) and 6c. All antisera are commercially available and antiserum $6 \mathrm{~b}$ obtained from the supplier after 1 January 2009 is antiserum $6 b^{*}$. All serotype $6 \mathrm{C}$ isolates were further characterised using multi-locus sequence typing.

Results: When retesting all 96 original serotype 6A isolates by PCR and the Neufeld test, $29.6 \%$ (24 of 81 ) of the invasive isolates in Denmark from 2007 and 2008 were recognised as serotype 6C. In addition, three of eight old isolates originally serotyped as 6A were identified to be serotype 6C. The oldest serotype 6C isolate was from 1962. The serotype 6C isolates belonged to eleven different sequence types (ST) and nine clonal complexes (CC), ST1692 (CC395), ST386 (CC386) and ST481 (CC460) were the predominant types.

Conclusions: We tested a novel polyclonal antiserum $6 \mathrm{~d}$, as well as modified antiserum $6 b^{*}$, provided a scheme for the serotyping of S. pneumoniae serogroup 6 using the Neufeld test and compared the serotyping method with PCR based methods. The two types of methods provided the same results. In future, it will, therefore, be possible to test also serotype $6 \mathrm{C}$ in accordance to the standard method for serotyping of S. pneumoniae recommended by WHO.

Among all invasive isolates from Denmark 2007 and 2008, serotype 6C constituted 29.6\% of the original serotype 6A isolates. The serotype $6 \mathrm{C}$ isolates were found to be diverse belonging to a number of different STs and CCs of which most have been observed in other countries previously. Serotype 6C is regarded as an "old" serotype being present among S. pneumoniae isolates in Denmark for at least 48 years. The genetic diversity of serotype $6 \mathrm{C}$ isolates and their genetic relationship to other serotypes suggested that serotype $6 \mathrm{C}$ strains may have arisen from several different independent recombination events involving different parental strains such as serotypes 6A, 6B, $23 \mathrm{~F}$ and 4 .
\end{abstract}

\footnotetext{
* Correspondence: IIm@ssi.dk

${ }^{1}$ Neisseria and Streptococcus Reference Laboratory, Department for Microbiological Surveillance and Research, Statens Serum Institut, Artillerivej, Copenhagen, Denmark

Full list of author information is available at the end of the article
} 


\section{Background}

In 2007, Park et al. [1] identified a novel serotype among Streptococcus pneumoniae serogroup 6 and named it serotype $6 \mathrm{C}$. This novel serotype was identified by the use of monoclonal antibodies and verified by sequencing of the capsule gene locus $[1,2]$. Interestingly, serotype $6 \mathrm{C}$ was found among isolates that were originally identified as serotype 6A using the WHO recommended standard serotyping method of S. pneumoniae, the Neufeld test [3]. To our knowledge, it was the first time a novel serotype was found among isolates that were easily serotypeable. In the past, novel serotypes were found among isolates that were non-serotypeable with the available antisera or isolates that showed odd combinations of specific reactions with the antisera.

The genetic difference between serotypes $6 \mathrm{~A}$ and $6 \mathrm{C}$ is the $w c i \mathrm{~N}$ gene [2] encoding a transferase resulting in an altered composition of the polysaccharide capsule. This gene may be used to distinguish serotype $6 \mathrm{~A}$ from $6 \mathrm{C}$ and as soon as the news concerning this novel serotype was out, many laboratories started testing for serotype $6 \mathrm{C}$ using PCR [4-7]. Subsequently, serotype $6 \mathrm{C}$ has been detected among invasive isolates [8] as well as non-invasive [5] and carriage isolates [9] and to date serotype 6C has been reported in the following countries: Canada, the U.S., Mexico, Brazil, the Netherlands, Portugal, South Africa, Korea, China and Australia [10,6,8,9,11]. These countries represent most continents. Serotype $6 \mathrm{C}$ is, therefore, not considered a rare serotype and it is expected that it will be found in all parts of the world. For that reason, it is of interest to be able to identify serotype $6 \mathrm{C}$ using the Neufeld test and typespecific polyclonal antisera as is the case for the 90 other serotypes.

The aim of this study was to evaluate with the Neufeld test a novel S. pneumoniae serotype 6C type specific polyclonal antiserum raised in rabbits. This novel antiserum has been commercially available since 1 January 2009. In addition, serotype $6 \mathrm{C}$ isolates found in Denmark in 2007 and 2008 as well as eight older serotype $6 \mathrm{~A}$ isolates were characterised.

\section{Methods}

\section{Bacterial isolates}

In this study, 181 clinical Streptococcus pneumoniae isolates (one isolate per case) from 2007 and 2008 were examined. Of these isolates, 96 had previously been typed as serotype $6 \mathrm{~A}$ and 85 as serotype $6 \mathrm{~B}$. The isolates were received in the reference laboratory from Danish clinical microbiological laboratories. Ethical approval was not needed for this study. The sample origin of the isolates is shown in Table 1. In addition, eight older isolates from the period 1952 to 1987, which had earlier been serotyped as $6 \mathrm{~A}$ were examined. As positive
Table 1 Overview of analysed S. pneumoniae serotype 6C

\begin{tabular}{lrrr}
\hline Serotype & $\begin{array}{r}6 \mathbf{A} \% \\
(\mathbf{n})\end{array}$ & $\begin{array}{r}\mathbf{6 B} \\
\mathbf{( n )}\end{array}$ & $\begin{array}{r}\mathbf{6 C} \\
\mathbf{6}(\mathbf{n})\end{array}$ \\
\hline Invasive isolates & & & \\
\hline blood & $84.2(48)$ & $90.6(58)$ & $79.2(19)$ \\
cerebrospinal fluid & $14.0(8)$ & $6.3(4)$ & $16.7(4)$ \\
other sterile site & $1.8(1)$ & $3.1(2)$ & $4.2(1)$ \\
Proportion of serogroup 6 & $39.3(57)$ & $44.1(64)$ & $16.6(24)$ \\
6C of original 6A & & & $29.6(24$ of 81) \\
\hline Non-invasive isolates & & & \\
\hline eye & $25.0(3)$ & $9.5(2)$ & \\
ear & $33.3(4)$ & $38.1(8)$ & \\
other non-sterile site & $41.7(5)$ & $52.4(11)$ & \\
Proportion of serogroup 6 & $33.3(12)$ & $58.3(21)$ & \\
6C of original 6A & & & $20.0(3$ of 15) \\
\hline All isolates & & & \\
\hline Proportion of serogroup 6 & $38.1(69)$ & $47.0(85)$ & \\
6C of original 6A & & & $28.1(27$ of 96) \\
\hline
\end{tabular}

Analysed S. pneumoniae serotype $6 C$ isolates compared to other serogroup 6 isolates from Denmark 2007 and 2008.

controls, we used serotype $6 \mathrm{C}$ isolates identified in two other countries, one isolate from the Netherlands (Peter Hermans, Nijmegen, The Netherlands) and three isolates from the U.S. (Michael Jacobs, Cleveland, Ohio).

Isolates were grown on $10 \%$ blood agar plates (SSI Diagnostica, Hilleroed, Denmark) at $36^{\circ} \mathrm{C}$ in air with $5 \%$ $\mathrm{CO}_{2}$ and stocks of isolates were stored at $-80^{\circ} \mathrm{C}$ in beef broth with $10 \%$ glycerol (SSI Diagnostica). Bacterial chelex-solution lysates were used as DNA templates for PCR.

All isolates were tested for susceptibility to antimicrobial agents as described in the DANMAP 2008 report http://www.danmap.org.

\section{PCR for identification of serotype $6 \mathrm{C}$}

For PCR1, primers 5106 (5-TACCATGCAGGGTGGAATGT) [2] and 3101 (5-CCATCCTTCGAGTATTGC) [12] were used. For PCR2, primers 6A-N-6195 (5TTGGACAATCTGGAAAGATATTG) and 6A-N-7642 (5-GCTTTTTTAGCAGGCGACATAG) were used (numbers in the PCR2 primer names refers to the 5 'annealing site of the primer to sequence [GenBank: EF538714]). PCR was performed using a $25 \mu \mathrm{l}$ PCR mix with $12.5 \mu \mathrm{l}$ HotstarTaq Mastermix (Qiagen, Hamburg, Germany), $0.5 \mathrm{mM}$ additional $\mathrm{MgCl}_{2}, 0.2 \mu \mathrm{M}$ of the relevant primers and $2 \mu \mathrm{l}$ DNA-template. The PCR programme used was; $15 \mathrm{~min}$ at $95^{\circ} \mathrm{C}, 35 \mathrm{cycles}$ of $30 \mathrm{sec}$ at $95^{\circ} \mathrm{C}, 30 \mathrm{sec}$ at $50^{\circ} \mathrm{C}$ $\left(52^{\circ} \mathrm{C}\right.$ for PCR2) and $90 \mathrm{sec}$ at $72^{\circ} \mathrm{C}$. The PCR was finalised by $10 \mathrm{~min}$ at $72^{\circ} \mathrm{C}$. The presence and quality of the PCR fragments was tested by gel-electrophoresis on $2 \% \mathrm{E}$-gels (Invitrogen A/S, Taastrup, Denmark). 
PCR1 resulted in PCR fragment sizes of $1,45 \mathrm{~kb}$ from serotype $6 \mathrm{~A}$ and $1,25 \mathrm{~kb}$ from serotype 6C. PCR2 resulted in an 2,00 kb PCR fragment from serotype 6A and an 1,80 kb fragment from serotype $6 \mathrm{C}$.

\section{Sequence determination of wciN}

Excess primers and nucleotides in the solution containing the PCR fragments from PCR1 or PCR2 were inactivated with ExoSap $\mathrm{IT}^{\oplus}$ as described by the manufacturer (USB Corporation, Cleveland, USA) before sequencing. Both strands of the PCR fragments were sequenced using $0.2 \mu \mathrm{M}$ of the relevant primers, BigDye Terminator 3.1 Cycle Sequencing Kit (Applied Biosystems, Foster City, USA) and an ABI-prisme 3100 Genetic Analyzer (Applied Biosystems) as recommended by the manufacturer.

\section{Serotype determination and test of serotype $6 C$ type specific antisera}

Serogroup determination was performed by agglutination test using Pneumotest Latex (SSI Diagnostica). Briefly, a culture of each isolate was grown in serum broth (SSI Diagnostica) overnight at $36^{\circ} \mathrm{C}$ in air with $5 \%$ $\mathrm{CO}_{2}$. An aliquot of $10 \mu \mathrm{l}$ culture and $10 \mu \mathrm{l}$ of latex suspension were placed next to each other on a cardboard reaction card, mixed and spread with a wooden toothstick followed by rocking the card from side to side. Each isolate was tested for reactions in all latex pools at the same time. Positive reactions showed as clear agglutination reactions within $10-20 \mathrm{sec}$. In the case of serogroup 6, these were positive reactions in latex pool B and Q. Serotype determination was performed with the Neufeld test using S. pneumoniae type specific rabbit antisera as recommended by the manufacturer (SSI Diagnostica). In this case, the factor antisera used were 6b, 6b* (absorbed free for cross reactions to serotype $6 \mathrm{C}), 6 \mathrm{c}$ and the novel antiserum $6 \mathrm{~d}$. Briefly, isolates were grown on $10 \%$ blood agar plates overnight at $36^{\circ} \mathrm{C}$ in air with $5 \% \mathrm{CO}_{2}$. A small amount of bacteria from the plate was suspended in an aliquot of 1-2 $\mu$ l saline placed on a microscope slide. Finally, $1-2 \mu \mathrm{l}$ factor antiserum was added to the bacterium-saline suspension with an $1 \mu \mathrm{l}$ plastic inoculation needle. A glass cover slip was placed on the mixture, a drop of immersion oil added and the bacteria were inspected in a light microscope with $100 \times$ magnification, phase-contrast and a green filter. Each isolate was tested for reaction with all factor antisera within the group at the same time. A positive reaction was observed as a swelling of the bacterium and capsule, often agglutination also occurred.

Multi locus sequence typing (MLST)

Sequence types were determined as described at http:// spneumoniae.mlst.net/.

\section{Data analysis}

All sequences were analysed using the software BioNumerics (Applied Math, Sint-Martens-Latem, Belgium) and sequence types identified with the information provided at http://spneumoniae.mlst.net/. Clonal relationships of sequence types and predictions of founders were analysed using the programme eBURST and the complete MLST S. pneumoniae database at http:// spneumoniae.mlst.net/. Sequences of $w c i \mathrm{~N}$ were compared to the sequence of S. pneumoniae CHPA388 [GenBank: EF538714], sequence and amino acid numbers refer to that sequence.

Predictions of the protein secondary structure and the amino acid accessibility was analysed using the programme NetSurfP at http://www.cbs.dtu.dk/services/ NetSurfP/[13].

\section{Results}

Genetic identification of S. pneumoniae serotype 6C isolates by PCR and sequencing of the wciN gene

Of all 96 original serotype 6A isolates from 2007 and 2008, 28.1\% $(\mathrm{n}=27)$ were tested to be serotype $6 \mathrm{C}$ by both PCR1 and PCR2 described in Methods. The PCR fragments from all isolates had the expected sizes and were similar to those from the positive controls of serotype $6 \mathrm{C}$ isolates identified in two different countries.

The coding region of the $w c i \mathrm{~N}$ genes of all $27 \mathrm{PCR}$ detected $6 \mathrm{C}$ isolates were $100 \%$ identical among the isolates. The genes showed $99.7 \%$ similarity to the $w c i \mathrm{~N}$ gene of 6C [GenBank: EF538714] published by Park et al 2007 and $99.9 \%$ similarity to the four other published sequences [GenBank: EF538716, EF538717, EF538715 and EF538718]. Compared to [GenBank: EF538714] sequence, the nucleotide changes were T65A, C541A and G677T. These changes did result in amino acid changes of the WciN protein of F22Y, H181N and G226V, however, these changes did not alter the predictions of the secondary structure and the amino acid accessibility analysed using the programme NetSurfP at http://www.cbs. $\mathrm{dtu} . \mathrm{dk} /$ services/NetSurfP/[13]. Using this programme, amino acids 22 and 181 were most likely located in alpha-helixes and amino acid 226 was most probably part of a beta-strand; all three amino acids were predicted to have low relative and absolute surface accessibility.

\section{Test of S. pneumoniae serotype $6 \mathrm{C}$ type specific polyclonal factor antiserum $6 \mathrm{~d}$}

A novel type specific rabbit antiserum, named factor antiserum $6 \mathrm{~d}$, was tested in addition to the existing factor antisera $6 \mathrm{~b}$ and $6 \mathrm{c}$ (Table 2) on all original serotypes $6 \mathrm{~A}(\mathrm{n}=96)$ and $6 \mathrm{~B}(85)$ isolates. Using the Neufeld test, all serotype $6 \mathrm{~A}$ isolates detected by PCR $(\mathrm{n}=69)$ showed positive and specific reactions with factor antiserum $6 \mathrm{~b}$. All serotype $6 \mathrm{~B}$ isolates showed positive and 
Table 2 Serotyping scheme for S. pneumoniae serogroup 6

\begin{tabular}{cccccc}
\hline Serotype & \multicolumn{5}{c}{ Factor serum } \\
\hline & $6 \mathrm{a}$ & $6 \mathrm{~b}$ & $6 \mathrm{~b}^{*}$ & $6 \mathrm{c}$ & $6 \mathrm{~d}$ \\
\hline $6 \mathrm{~A}$ & $\mathrm{x}$ & $\times$ & $\times$ & & \\
$6 \mathrm{~B}$ & $\mathrm{x}$ & & & $\times$ & \\
$6 \mathrm{C}$ & $\times$ & $\times$ & & & $\times$ \\
\hline
\end{tabular}

* absorbed with 6C

Serotyping scheme for S. pneumoniae serogroup 6 using the Neufeld test and polyclonal factor antisera. Scheme for determining the serotype from the pattern of positive reactions $(\mathrm{x})$ between $\mathrm{S}$. pneumoniae and type specific polyclonal factor antisera.

specific reactions with factor antiserum 6c. All serotype $6 \mathrm{C}$ isolates detected by PCR $(\mathrm{n}=27)$ showed positive and specific reaction with factor antiserum $6 \mathrm{~d}$; however, in addition the serotype $6 \mathrm{C}$ isolates showed positive and specific reactions with factor antiserum $6 \mathrm{~b}$. Therefore, a modified factor antiserum $6 b^{*}$ absorbed free for cross reactions to serotype $6 \mathrm{C}$ was produced and tested. This antiserum should react specifically with serotype $6 \mathrm{~A}$ but not $6 \mathrm{C}$. All serotypes $6 \mathrm{~A}$ and $6 \mathrm{C}$ isolates were tested and only serotype $6 \mathrm{~A}$ isolates showed positive and specific reactions with factor antiserum $6 b^{*}$. The resulting serotyping scheme for serogroup 6 , including the novel factor antiserum $6 \mathrm{~d}$ and the modified antiserum $6 b^{*}$, is shown in Table 2.

\section{Origin of serotype 6C isolates from 2007 and 2008} compared to other serogroup 6 isolates from Denmark Upon retesting original serotype $6 \mathrm{~A}$ isolates by PCR and the Neufeld test, a proportion of $29.6 \%$ (24 of 81 ) of the invasive isolates were serotype $6 \mathrm{C}$ (Table 1 ). These isolates were from 23 patients with a mean age of 53.5 years (range 0 to 92 years). In the same period of time from the same geographic area, there were 56 serotype $6 \mathrm{~A}$ and 62 serotype $6 \mathrm{~B}$ isolates (Table 1 ). The serotype 6A isolates were from patients with a mean age of 63.0 years (range 0-91 years) and the serotype 6B isolates were from patients with a mean age of 58.9 (range $0-99$ ). Of the $6 \mathrm{C}$ isolates, $48 \%$ were from females compared to $54 \%$ and $56 \%$ of serotype $6 \mathrm{~A}$ and $6 \mathrm{~B}$ isolates, respectively.

All invasive isolates were tested for susceptibility to the two antimicrobial agents penicillin and erythromycin, $3.7 \%(n=2)$ of serotype $6 \mathrm{~A}, 6.5 \%(4)$ of serotype $6 \mathrm{~B}$ and 4.3 (1) of serotype $6 \mathrm{C}$ were penicillin non-susceptible and $3.7 \%(\mathrm{n}=2)$ of serotype $6 \mathrm{~A}, 9.7 \%(6)$ of serotype $6 \mathrm{~B}$ and $13 \%$ (3) of serotype $6 \mathrm{C}$ were erythromycin resistant.

\section{Clonal relation of serotype $6 \mathrm{C}$ isolates from Denmark using multi locus sequence typing and antimicrobial resistance pattern}

Among all serotype 6C isolates, eight different sequence types (STs) were found. The most prevalent STs were
ST1692 (n = 10), ST386 (6) and ST481 (5) (Table 3). Most serotype $6 \mathrm{C}$ isolates were susceptible to the antimicrobial agents tested and the non-susceptible isolates were found to belong to two STs, ST386 and ST1379 (Table 3).

To evaluate the clonality of the serotype $6 \mathrm{C}$ isolates, the founder of the clonal complex (CC) for each ST was predicted using eBURST. The eight STs were found to belong to seven different CCs (Table 3). By this method, the serotype $6 \mathrm{C}$ isolates were found to be diverse.

\section{Test of old serotype $6 \mathrm{~A}$ isolates}

Eight old isolates originally serotyped as serotype 6A isolates were also tested. Three of them were typed to be serotype $6 \mathrm{C}$ by the PCR methods and the Neufeld test using the novel antisera. These three isolates were from the years 1962, 1968, and 1987. The wciN gene sequences were identical to the $6 \mathrm{C}$ isolates analysed from 2007 to 2008, except for one of the isolates that had a silent A7298G sequence change. The three isolates all had different STs, ST3029, ST2185 and STnew1 belonging to three different CCs.

\section{Discussion}

This study compared two different methods to identify serotype 6C S. pneumoniae; a phenotypic method, the Neufeld test, based on the use of a novel polyclonal factor antiserum $6 \mathrm{~d}$ specific for serotype $6 \mathrm{C}$ and a genotypic method based on PCR identification of the wciN gene size difference between serotypes $6 \mathrm{C}$ and $6 \mathrm{~A}$. The two methods provided the same results when testing 96 original serotype $6 \mathrm{~A}$ isolates.

In addition to the novel antiserum $6 \mathrm{~d}$, antiserum $6 \mathrm{~b}$ that showed specificity to both serotypes $6 \mathrm{~B}$ and $6 \mathrm{C}$ was altered to antiserum $6 \mathrm{~b} *$ specific only to serotype $6 \mathrm{~B}$ and not to serotype $6 \mathrm{C}$. These novel antisera together with the known sera, should provide a sufficient panel of antisera to be able to distinguish the currently known serotypes of serogroup 6. All antisera are commercially available and antiserum $6 \mathrm{~b}$ obtained from the supplier after 1 January 2009 is antiserum 6b*.

With this study we have shown that it was possible to produce useful polyclonal antisera to be able to distinguish serotype $6 \mathrm{C}$ from the other serotypes within serogroup 6 . The specificity of the factor serum $6 \mathrm{~d}$ was in agreement with a recent validation study of this factor serum performed by a different research group [14]. However, in that study, factor serum $6 \mathrm{~b}$ and not $6 \mathrm{~b}^{*}$ was used, which is why they observed serotype $6 \mathrm{C}$ to be positive in both factor sera $6 \mathrm{~d}$ and $6 \mathrm{~b}$.

Very recently, a research group at CDC also showed that it was possible to produce a specific polyclonal antiserum to distinguish serotype $6 \mathrm{C}$ from other serogroup 6 isolates following the same strategy as described here; 
Table 3 Sequence types (STs) and clonal complexes (CCs) of serotype $6 \mathrm{C}$

\begin{tabular}{|c|c|c|c|c|c|}
\hline \multicolumn{6}{|c|}{$2007-2008$ is olates } \\
\hline $\begin{array}{l}\text { Number of } \\
\text { isolates, } n\end{array}$ & ST & $\begin{array}{c}\mathrm{CC} \\
\text { (founder)* }\end{array}$ & $\begin{array}{l}\text { ST Antimicrobial resistance } \\
\text { profile }(n)\end{array}$ & $\begin{array}{l}\text { ST has been found in serotypes } \\
\text { (countries) }{ }^{\#}\end{array}$ & $\begin{array}{l}\text { CC has been found in serotypes } \\
\text { (countries) }^{\#}\end{array}$ \\
\hline 10 & 1692 & 395 & & 6A (UK, Switzerland) 6C (Portugal) & 6A (UK, U.S.) 6C (Portugal, Italy) \\
\hline 6 & 386 & 386 & $\begin{array}{c}\text { PEN, ERY, CLI, TET (3) ERY, CLI, } \\
\text { TET (3) }\end{array}$ & $\begin{array}{l}\text { 6B (Portugal, Italy, Lebanon, } \\
\text { Germany) }\end{array}$ & $\begin{array}{l}\text { 6B (Portugal, Italy, Lebanon, } \\
\text { Germany) }\end{array}$ \\
\hline 5 & 481 & 460 & & $6 \mathrm{~A}$ (Finland) & 6A (UK, U.S., France) \\
\hline 3 & 1379 & 1600 & ERY (1) & 6A (Sweden, U.S.) 6C (U.S., Australia) & 6A (UK, U.S.) \\
\hline 1 & 398 & 473 & & $6 \mathrm{~A}(\mathrm{UK})$ & $\begin{array}{l}\text { 6A (UK, U.S., France, } \\
\text { Greece, Australia, Germany) } \\
\text { 6B (Australia, Hungary) } \\
\text { 6C (U.S.) }\end{array}$ \\
\hline 1 & 600 & 600 & & 6A (Polan) 6C (Australia) & 6A (Polan) 6C (Australia) \\
\hline 1 & 1714 & 395 & & 6A (UK) 6C (Portugal) 23F (Norway) & 6A (UK, U.S.) 6C (Portugal, Italy) \\
\hline \multicolumn{6}{|l|}{ Old isolates } \\
\hline 1 & 2185 & 2185 & & 6A (Polan) 6C (Portugal) & 6A (Polan) 6C (Portugal) \\
\hline 1 & 3029 & 3304 & & $6 \mathrm{~A}($ (U.S.) & 4 (The Gambia) \\
\hline 1 & new1 & & & & \\
\hline
\end{tabular}

* in accordance to eBURST using the complete MLST database and a minimum similarity of six identical loci

\#information in accordance to the http://www.mlst.net accessed 26. June 2010

Sequence types (STs) and clonal complexes (CCs) of serotype 6C isolates from Denmark in relation to those found previously in other countries.

their antisera are, however, currently not commercially available [15].

One different phenotypic method based on monoclonal antiserum identifying one specific epitope for the identification of serotype $6 \mathrm{C}$ has been reported [1]. In contrast, several genetically based methods based on the identification of the $w c i \mathrm{~N}$ gene or sizes of specific PCR fragments have been reported before $[2,7,10,6]$.

With the discovery of serotype $6 \mathrm{C}$, it became clear that new technology, especially genetically based methods, will change the number of known serotypes and the division of groups into serotypes. It also became clear that it is possible to use different methods for determining a serotype. More methods provide possibilities for more laboratories to perform serotype determination of isolates, which is of high value when estimating and evaluating vaccine efficacies and vaccine failures. Different methods for serotype determination will complement each other, but all methods should be compared to one international standardised reference method.

The international reference method and the WHO recommended method for the serotyping of S. pneumoniae is the Neufeld test and the use of type specific polyclonal antisera. With the production of the novel antisera reported here, the Neufeld test can continue to be the international reference method.

In 2007 and 2008, serotype 6C constituted 28.1\% (27 of 96) of all original serotype $6 \mathrm{~A}$ isolates received in the Danish national reference laboratory. Among all invasive isolates from the same time period, serotype $6 \mathrm{C}$ constituted $29.6 \%$ (24 of 81 ) of the original serotype $6 \mathrm{~A}$ isolates. This corresponds to $1.2 \%$ of all invasive S. pneumoniae isolates and an incidence of 0.22 per 100,000 persons. This proportion is at the same level as observed in other studies. Among isolates in Cleveland, the U.S., from 1999 to $2007,6 \mathrm{C}$ was observed to constitute $26 \%$ of the previous serotype $6 \mathrm{~A}$ isolates [5], among invasive isolates from Brazil 1996 to 2007, 34\% of previous serotype $6 \mathrm{~A}$ isolates were found to be serotype $6 \mathrm{C}$ [10], and among Australian invasive isolates previously defined as serotype 6A, serotype 6C constituted 31\% [7]. In contrast, serotype $6 \mathrm{C}$ was found to constitute only $5 \%$ of invasive isolates from children in South Africa in 2005-2006 [11] and only $0.3 \%$ among previously defined 6A carriage isolates from Dutch children in 2002 [4]. These studies showed that serotype $6 \mathrm{C}$ is widely spread in the world and that it may constitute a higher or lower proportion of the previously defined serotype $6 \mathrm{~A}$ isolates. The proportion of serotype $6 \mathrm{C}$ compared to the other serotypes of serogroup 6 as well as the proportion of serotype $6 \mathrm{C}$ compared to all serotypes is expected to change with time and may change differently in different areas with use of vaccines and antimicrobial agents as factors that can provoke serotype distribution changes. Such changes within serogroup 6 have already been observed by the Active Bacterial Core Surveillance Team in the U.S. They tested $16 \%$ invasive isolates of original serotype 6A in 1999 to be serotype 6C; however, this changed to $65 \%$ and $69 \%$ in 2006 and 2007 , respectively. The change corresponded to a change in the incidence of $6 \mathrm{C}$ invasive pneumococcal disease from 0.22 in 1999 to 0.58 in 2007 [6]. The dramatic change 
was related to the introduction of the 7-valent pneumococcal vaccine in 2000 causing a decline in the incidence of both serotype $6 \mathrm{~B}$ and $6 \mathrm{~A}$ cases, but an increase in the proportion of serotype $6 \mathrm{C}$ cases [ref [6]]. This was probably observed, as the vaccine protects against invasive infections with serotype $6 \mathrm{~B}$, but in addition the vaccine has been shown to have a high level of cross-protection against serotype $6 \mathrm{~A}$ but not $6 \mathrm{C}$ [16]. Similar changes in the distribution of serotypes within serogroup 6 can be expected in Denmark in the future, as the vaccine was introduced in 2007.

The sample origin (sample material, age and sex of person) and antibiotic resistance level of serotype $6 \mathrm{C}$ were quite similar to that found for the other serogroup 6 isolates. The proportion of antibiotic non-susceptible $6 \mathrm{C}$ was low compared to observations done in the U.S. $[5,6,17]$, but that may also change as observed by the Active Bacterial Core Surveillance Team in the U.S. after introduction of the vaccine [ref [6]].

Among all Danish serotype 6C isolates from 2007 and 2008, ten different STs belonging to nine CCs were found and among the three old $6 \mathrm{C}$ isolates three different STs and CCs were found. The serotype 6C isolates in Denmark were, therefore, regarded as diverse. Except for ST386 and STnew1, all of the serotype 6C STs had been identified before in relation to serotype $6 \mathrm{~A}$ from a number of different countries (Table 3 ). It would be interesting to re-analyse those serotype $6 \mathrm{~A}$ isolates as they may turn out to be serotype $6 \mathrm{C}$ with the current knowledge. Thus ST481 and CC460 had only been related to serotype $6 \mathrm{~A}$, they may, therefore, be true serotype $6 \mathrm{~A}$ and not $6 \mathrm{C}$ if re-analysed. Four of the STs were previously found in relation to serotype $6 \mathrm{C}$, all from geographically distant countries like Portugal, Australia and the U.S. (Table 3). One ST, ST386 had previously only been found in relation to serotype $6 \mathrm{~B}$ in several countries (Table 3). All of the CCs, except for CC386 and CC3304, had also been observed in a number of countries in relation to serotypes $6 \mathrm{~A}$ or $6 \mathrm{C}$ (Table 3 ). CC386 had only been found in serotype $6 \mathrm{~B}$ isolates and in addition to $6 \mathrm{~A}$ and $6 \mathrm{C}, \mathrm{CC} 473$ had also been observed in serotype 6B. CC395 had in addition to serotypes $6 \mathrm{~A}$ and $6 \mathrm{C}$ also been observed in serotype $23 \mathrm{~F}$ whereas CC3304 was previously only observed in serotype 4 (Table 3 ). All of these observations confirm the suggestion by Carvalho et al. 2009 that serotype 6C strains arose from independent recombination events. Thus, in contrast to that study suggesting these involved parental strains of serotypes $6 \mathrm{~A}$ and $6 \mathrm{C}$, this study suggests that these events involve at least serotypes $6 \mathrm{~A}, 6 \mathrm{~B}$ and possibly also serotypes $23 \mathrm{~F}$ and 4 as parental strains. With this study, it was also confirmed that serotype $6 \mathrm{C}$ is an "old" serotype being present among S. pneumoniae isolates in Denmark for at least 48 years. This time span would allow the possibility that $6 \mathrm{C}$ strains may have arisen from several different independent recombination events involving different parental strains.

\section{Conclusions}

In this study we tested a novel polyclonal antiserum $6 \mathrm{~d}$, as well as a modified antiserum $6 b^{*}$, provided a scheme for serotyping of S. pneumoniae serogroup 6 using the Neufeld test and compared the serotyping method with PCR based methods. The two types of methods provided the same results. In the future, it will therefore be possible to test also serotype $6 \mathrm{C}$ in accordance to the WHO recommended standard method for serotyping of S. pneumoniae.

Among all invasive isolates from Denmark 2007 and 2008 , serotype $6 \mathrm{C}$ constituted $29.6 \%$ of the original serotype $6 \mathrm{~A}$ invasive isolates. The serotype $6 \mathrm{C}$ isolates were found to be diverse belonging to a number of different STs and CCs of which most had been observed in other countries previously. Serotype $6 \mathrm{C}$ is regarded as an "old" serotype with the presence among S. pneumoniae isolates in Denmark for at least 48 years. The genetic diversity and relationship of the analysed $6 \mathrm{C}$ strains suggest that serotype 6C strains may have arisen from several different independent recombination events involving different parental strains such as serotypes $6 \mathrm{~A}$, $6 \mathrm{~B}, 23 \mathrm{~F}$ and 4.

\section{Acknowledgements}

We thank the Danish departments of clinical microbiology for sending isolates to the Neisseria and Streptococcus Reference laboratory. Staff in the laboratories is thanked for their technical expertise and positive commitment to the work. This work was part of the National Surveillance of severe streptococcal infections funded by the Danish Ministry of the Interior and Health. Part of this study was presented at the Europneumo meeting, Bern, Switzerland, 2009.

Peter Hermans and Michael Jacobs are thanked for sharing 6C isolates.

\section{Author details}

${ }^{1}$ Neisseria and Streptococcus Reference Laboratory, Department for Microbiological Surveillance and Research, Statens Serum Institut, Artillerivej, Copenhagen, Denmark. ${ }^{2} S S I$ Diagnostica, Statens Serum Institut, Hilleroed, Denmark.

\section{Authors' contributions}

$\mathrm{LL}$ and MBK both contributed to this study by the conception and design of the study, MBK produced and provided the novel antisera, LL managed all laboratory work, collected data and did data analyses. LL drafted the manuscript and both $L L$ and MBK revised the manuscript critically. Both authors have approved the final manuscript.

\section{Competing interests}

The authors declare that they have no competing interests.

Received: 6 April 2010 Accepted: 24 September 2010

Published: 24 September 2010

\section{References}

1. Park $\mathrm{H}_{\text {, }}$ Pritchard DG, Cartee R, Brandao A, Brandileone MC, Nahm MH: Discovery of a new capsular serotype (6C) within serogroup 6 of Streptococcus pneumoniae. J Clin Microbiol 2007, 45:1225-1233. 
2. Park IH, Park S, Hollingshead SK, Nahm MH: Genetic basis for the new pneumococcal serotype, 6C. Infect Immun 2007, 75:4482-4489.

3. O'Brien KL, Nohynek H: Report from a WHO Working Group: standard method for detecting upper respiratory carriage of Streptococcus pneumoniae. Pediatr Infect Dis J 2003, 22:e1-11.

4. Hermans PW, Blommaart M, Park IH, Nahm MH, Bogaert D: Low prevalence of recently discovered pneumococcal serotype $6 \mathrm{C}$ isolates among healthy Dutch children in the pre-vaccination era. Vaccine 2008, 26:449-450.

5. Jacobs MR, Good CE, Bajaksouzian S, Windau AR: Emergence of Streptococcus pneumoniae serotypes $19 \mathrm{~A}, 6 \mathrm{C}$, and $22 \mathrm{~F}$ and serogroup 15 in Cleveland, Ohio, in relation to introduction of the proteinconjugated pneumococcal vaccine. Clin Infect Dis 2008, 47:1388-1395.

6. Carvalho MG, Pimenta FC, Gertz RE Jr, Joshi HH, Trujillo AA, Keys LE, et al: PCR-based quantitation and clonal diversity of the current prevalent invasive serogroup 6 pneumococcal serotype, $6 \mathrm{C}$, in the United States in 1999 and 2006 to 2007. J Clin Microbiol 2009, 47:554-559.

7. Jin P, Xiao M, Kong F, Oftadeh S, Zhou F, Liu C, et al: Simple, accurate, serotype-specific PCR assay to differentiate Streptococcus pneumoniae serotypes 6A, 6B, and 6C. J Clin Microbiol 2009, 47:2470-2474.

8. Jacobs MR, Bajaksouzian S, Bonomo RA, Good CE, Windau AR, Hujer AM, et al: Occurrence, distribution, and origins of Streptococcus pneumoniae Serotype 6C, a recently recognized serotype. I Clin Microbiol 2009, 47:64-72.

9. Nunes S, Valente C, Sa-Leao R, de LH: Temporal trends and molecular epidemiology of recently described serotype $6 \mathrm{C}$ of Streptococcus pneumoniae. J Clin Microbiol 2009, 47:472-474.

10. Campos LC, Carvalho MG, Beall BW, Cordeiro SM, Takahashi D, Reis MG, et al: Prevalence of Streptococcus pneumoniae serotype $6 \mathrm{C}$ among invasive and carriage isolates in metropolitan Salvador, Brazil, from 1996 to 2007. Diagn Microbiol Infect Dis 2009, 65:112-115.

11. du PM, von GA, Madhi SA, Hattingh O, de GL, Klugman KP: Serotype 6C is associated with penicillin-susceptible meningeal infections in human immunodeficiency virus (HIV)-infected adults among invasive pneumococcal isolates previously identified as serotype $6 \mathrm{~A}$ in South Africa. Int J Antimicrob Agents 2008, 32(Suppl 1):S66-S70.

12. Mavroidi A, Godoy D, Aanensen DM, Robinson DA, Hollingshead SK, Spratt BG: Evolutionary genetics of the capsular locus of serogroup 6 pneumococci 1. J Bacteriol 2004, 186:8181-8192.

13. Petersen B, Petersen TN, Andersen P, Nielsen M, Lundegaard C: A generic method for assignment of reliability scores applied to solvent accessibility predictions. BMC Struct Biol 2009, 9:51.

14. Jacobs MR, Dagan R, Bajaksouzian S, Windau AR, Porat N: Validation of factor $6 \mathrm{~d}$ antiserum for serotyping Streptococcus pneumoniae serotype 6C. J Clin Microbiol 2010, 48:1456.

15. Melnick N, Thompson TA, Beall BW: Serotype-specific typing antisera for pneumococcal serogroup 6 serotypes 6A, 6B, and 6C. J Clin Microbiol 2010, 48:2311.

16. Park IH, Moore MR, Treanor JJ, Pelton SI, Pilishvili T, Beall B, Shelly MA, Mahon BE, Nahm MH, Active Bacterial Core Surveillance Team: Differential effects of pneumococcal vaccines against serotypes $6 \mathrm{~A}$ and $6 \mathrm{C}$. J Infect Dis 2008, 198:1818.

17. Gertz RE Jr, Li Z, Pimenta FC, Jackson D, Juni BA, Lynfield R, Jorgensen JH, Carvalho Mda G, Beall BW, Active Bacterial Core Surveillance Team: Increased penicillin nonsusceptibility of nonvaccine-serotype invasive pneumococci other than serotypes $19 \mathrm{~A}$ and $6 \mathrm{~A}$ in post-7-valent conjugate vaccine era. J Infect Dis 2010, 201:770.

\section{Pre-publication history}

The pre-publication history for this paper can be accessed here: http://www.biomedcentral.com/1471-2334/10/282/prepub

doi:10.1186/1471-2334-10-282

Cite this article as: Lambertsen and Kerrn: Test of a Novel Streptococcus pneumoniae Serotype 6C Type Specific Polyclonal Antiserum (Factor Antiserum 6d) and Characterisation of Serotype 6C Isolates in Denmark. BMC Infectious Diseases 2010 10:282.

\section{Submit your next manuscript to BioMed Central and take full advantage of:}

- Convenient online submission

- Thorough peer review

- No space constraints or color figure charges

- Immediate publication on acceptance

- Inclusion in PubMed, CAS, Scopus and Google Scholar

- Research which is freely available for redistribution

Submit your manuscript at www.biomedcentral.com/submit 